\title{
Mechanism and regulation of intestinal copper absorption
}

Yasuhiro Nose, Dennis J Thiele.

Department of Pharmacology and Cancer Biology, Duke University School of Medicine, Durham, North Carolina, USA

Copper $(\mathrm{Cu})$ is an essential cofactor for a broad variety of biological functions from mitochondrial energy generation and free radical detoxification to iron acquisition and peptide hormone maturation. It has been estimated that approximately $2.0 \mathrm{mg}$ dietary $\mathrm{Cu}$ is needed by humans each day, but the precise levels of $\mathrm{Cu}$ for adequate function in humans are relatively poorly understood (Milne, 1998). The ability of copper to assume two oxidation states, oxidized copper $\left(\mathrm{Cu}^{2+}\right)$ or reduced copper $\left(\mathrm{Cu}^{+}\right)$, provides the redox power to drive enzymatic reactions and the chemical variability to coordinate with distinct preferred sets of amino acid ligands to facilitate a variety of protein structures. For example, $\mathrm{Cu}^{+}$prefers thiol rich ligands and $\mathrm{Cu}^{2+}$ is often found associated with nitrogen or oxygen ligands (Davis and O'Halloran, 2008). While $\mathrm{Cu}$ is essential for normal mammalian growth and development, excess $\mathrm{Cu}$ is thought to engage in redox chemistry that generates damaging free radicals such as hydroxyl radical (Halliwell and Gutteridge, 1990). $\mathrm{Cu}$ has also been demonstrated to cause toxicity due to its ability to compete for iron incorporation into iron sulfur clusters (Macomber and Imlay, 2009).

Many of the nuts and bolts of $\mathrm{Cu}$ metabolism have been elucidated at the cellular level through both studies in microbes and through the analysis of human genetic disorders of $\mathrm{Cu}$ metabolism (Lutsenko and Petris, 2002 ; Puig et al. 2002; De Bie et al. 2007; Kim et al. 2008). These experiments reveal an impressive conservation of structure and function with respect to the proteins that carry out $\mathrm{Cu}$ homeostasis and in the fundamental tenet that there are extraordinarily low levels of intracellular free $\mathrm{Cu}$ (Rae et al. 1999). In mammalian cells $\mathrm{Cu}$ import is carried out, at least in part, by the $\mathrm{Ctr} 1$ protein, a homotrimeric channel-like protein that facilitates $\mathrm{Cu}^{+}$uptake with high affinity (Lee et al. 2002a; Puig and Thiele 2002; Nose et al. 2006b; De Feo et al. 2009). However, the observation that mouse embryonic fibroblasts lacking $\mathrm{Ctr} 1$ harbor an activity for $\mathrm{Cu}$ uptake that may have low affinity and may import $\mathrm{Cu}^{2+}$, suggests that there are alternative mechanisms for $\mathrm{Cu}$ absorption that must be defined (Lee et al. 2002b). Intracellular $\mathrm{Cu}$ is routed to proteins and compartments, as an essential part of the controlled distribution process, via $\mathrm{Cu}$ chaperone proteins (Rosenzweig and O'Halloran 2000; Luk et al. 2003; Robinson and Winge 2010) and the delivery of Cu to the secretory lumen, or its removal from cells, makes use of two $\mathrm{Cu}^{+}$transporting ATPases, ATP7A or ATP7B (Lutsenko and Petris 2002; Bartee and Lutsenko 2007). Given that $\mathrm{Cu}$ is essential but reactive, and there are very low levels of labile intracellular $\mathrm{Cu}$, it is clear that $\mathrm{Cu}$ homeostasis at the cellular level is very tightly controlled. Mechanisms for controlling $\mathrm{Cu}$ homeostasis have been reported to occur at the level of $\mathrm{Cu}$ induced transcription of genes encoding the metallothionein $\mathrm{Cu}$ binding proteins, protein trafficking in response to changing $\mathrm{Cu}$ levels and through changes in protein stability in response to $\mathrm{Cu}$ (Bertinato and L'Abbé 2003; Petris et al. 2003; Greenough et al. 2004; Nittis and Gitlin 2004; West and Prohaska 2004; Nose et al. 2010). However, little is known about how mammals regulate systemic $\mathrm{Cu}$ homeostasis.

While the regulation and maintenance of systemic $\mathrm{Cu}$ metabolism is critical to human health, severe genetic diseases of $\mathrm{Cu}$ metabolism exist and copper deficiency causes myeloneuropathy, anemia, cognitive disorders and cardiac hypertrophy (Prohaska 1983; Kumar and Low 2004; Madsen and Gitlin 2007). Dietary Cu is absorbed through the intestine, stored in the liver and mobilized into the circulation for provision to peripheral organs. To begin to understand how $\mathrm{Cu}$ is absorbed from the diet, we and others ascertained the subcellular location of the Ctr1 high affinity $\mathrm{Cu}^{+}$transporter in intestinal epithelial cell. While one study found $\mathrm{Ctr} 1$ on the basolateral membrane of Caco 2 cells and mouse intestinal epithelial cells (Zimnicka et al. 2007) the dominant observation in the field is that Ctr1 is localized to 
the apical surface of intestinal epithelial cells of mouse, rat and pig (Bauerly et al. 2004; Nose et al. $2006 \mathrm{a}$; Kuo et al. 2006; Nose et al. 2010). To begin to understand the potential role of $\mathrm{Ctr} 1$ in intestinal $\mathrm{Cu}$ absorption, we generated a Ctr1 floxed mouse to facilitate tissue-specific and temporal Ctr1 knock out mice. Consistent with a critical role for Ctr1 in dietary $\mathrm{Cu}$ absorption, mice bearing an intestinal epithelial cell-specific (IEC) loss of $\mathrm{Ctr} 1 \mathrm{demonstrated} \mathrm{Cu}$ deficiency in all peripheral tissues examined and developed severe cardiac hypertrophy, similar to what is observed in animals reared on a $\mathrm{Cu}$ deficient diet (Nose et al. 2006a). To explore whether there is a cardiac-intrinsic requirement for $\mathrm{Cu}$ or whether cardiac hypertrophy is a response to peripheral $\mathrm{Cu}$ deficiency, we constructed a cardiac-specific $\mathrm{Ctr} 1$ knock out mouse. Indeed, both fruit flies and mice lacking Ctr1 in heart tissue develop cardiac hypertrophy, indicating a cardiac specific requirement for $\mathrm{Cu}$.

Interestingly, mice with a cardiac-specific Ctr1 knock out send a signal back to intestinal epithelial cells and to the liver, the major $\mathrm{Cu}$ storage organ, to induce expression of the ATP7A $\mathrm{Cu}$ efflux transporter that moves more $\mathrm{Cu}$ across the IEC basolateral membrane and, presumably, out of the liver into the bloodstream (Kim et al. 2010). These results suggest the presence of a currently undefined systemic $\mathrm{Cu}$ homeostasis regulatory mechanism that allows the $\mathrm{Cu}$ status of the heart to be communicated to the $\mathrm{Cu}$ transport machinery expressed in tissues involved in $\mathrm{Cu}$ uptake and in $\mathrm{Cu}$ storage. Interestingly, serum from mice bearing a cardiac-specific Ctr1 knock out was able to induce ATP7A protein levels in Caco2 and other cell lines, as compared to serum from control mice, suggesting the involvement of a diffusible factor in the bloodstream for the communication of a $\mathrm{Cu}$ deficiency signal. Whether this signal represents a hypoxic response due to compromised cardiac function, a hormonal response or a $\mathrm{Cu}$-specific sensing mechanism remains to be elucidated.

The mechanisms of intestinal $\mathrm{Cu}$ transport, at a minimum, involve the apical membrane $\mathrm{Cu}^{+}$transporter $\mathrm{Ctr} 1$, intracellular $\mathrm{Cu}$ chaperones and the basolateral ATP7A $\mathrm{Cu}^{+}$efflux pump. While our understanding of the fundamental mechanism of action of these proteins is being intensely investigated, we know little about how this basic machinery is regulated and how the $\mathrm{Cu}$ status in peripheral tissues communicates back to the intestinal absorption machinery to regulate intake.

\section{Acknowledgements}

Work in our laboratory on mammalian copper homeostasis is supported by a grant from the National Institutes of Health (DK074192) to D.J.T.

\section{REFERENCES}

Bartee MY and Lutsenko S (2007) Hepatic copper-transporting ATPase ATP7B: function and inactivation at the molecular and cellular level. Biometals 20: 627-637.

Bauerly KA, Kelleher SL and Lönnerdal B (2004) Functional and molecular responses of suckling rat pups and human intestinal Caco-2 cells to copper treatment. J Nutr Biochem 15: 155-162.

Bertinato J and L'Abbé MR (2003) Copper Modulates the Degradation of Copper Chaperone for Cu,Zn Superoxide Dismutase by the 26 S Proteosome. J Biol Chem 278: 35071-35078.

Davis AV and O'Halloran TV (2008) A place for thioether chemistry in cellular copper ion recognition and trafficking. Nat Chem Biol 4: 148-151. 
De Bie P, Muller P, Wijmenga C and Klomp LWJ (2007) Molecular pathogenesis of Wilson and Menkes disease: correlation of mutations with molecular defects and disease phenotypes. J Med Genet 44: 673-688.

De Feo CJ, Aller SG, Siluvai GS, Blackburn NJ and Unger VM (2009) Three-dimensional structure of the human copper transporter hCTR1. Proc Natl Acad Sci USA 106: 4237-4242.

Greenough M, Pase L, Voskoboinik I, Petris MJ, Wilson O'Brien A and Camakaris J (2004) Signals regulating trafficking of Menkes (MNK; ATP7A) copper-translocating P-type ATPase in polarized MDCK cells. Am J Physiol Cell Physiol 287: C1463-C1471.

Halliwell B and Gutteridge JM (1990) Methods Enzymol. 186: 1-85.

Huffman DL and O'Halloran TV (2001) Function, Structure, and Mechanism of Intracellular Copper Trafficking Proteins. Annu Rev Biochem 70: 677-701.

Kim B-E, Nevitt T and Thiele DJ (2008) Mechanisms for copper acquisition, distribution and regulation. Nat Chem Biol 4: 176-185.

Kim B-E, Turski ML, Nose Y, Casad M, Rockman HA and Thiele DJ (2010) Cardiac Copper Deficiency Activates a Systemic Signaling Mechanism that Communicates with the Copper Acquisition and Storage Organs. Cell Metabol 11: 353-363.

Kumar N and Low PA (2004) Myeloneuropathy and anemia due to copper malabsorption. J Neurol 251: 747-749.

Kuo YM, Gybina AA, Pyatskowit JW, Gitschier J and Prohaska JR (2006) Copper Transport Protein (Ctr1) Levels in Mice Are Tissue Specific and Dependent on Copper Status J Nutr 136: 21-26.

Lee J, Peña MMO, Nose Y and Thiele DJ (2002a) Biochemical Characterization of the Human Copper Transporter Ctr1. J Biol Chem 277: 4380-4387.

Lee J, Petris MJ and Thiele DJ (2002b) Characterization of Mouse Embryonic Cells Deficient in the Ctr1 High Affinity Copper Transporter: Identification of a Ctr1-independent copper transport system. J Biol Chem 277: 4025340259.

Luk E, Jensen LT and Culotta VC (2003) The many highways for intracellular trafficking of metals. J Biol Inorg Chem 8: 803-809.

Lutsenko S and Petris MJ (2002) Function and Regulation of the Mammalian Copper-transporting ATPases: Insights from Biochemical and Cell Biological Approaches. J Membrane Biol 191, 1-12.

Macomber L and Imlay JA (2009) The iron-sulfur clusters of dehydratases are primary intracellular targets of copper toxicity. Proc Natl Acad Sci 106: 8344-8349.

Madsen E and Gitlin JD (2007) Copper and Iron Disorders of the Brain. Annu Rev Neurosci 30: 317-37.

Milne, D. B. (1998) Copper intake and assessment of copper status. Am J Clin Nutr 67 (suppl): 1041S-1045S.

Nittis T and Gitlin JD (2004) Role of Copper in the Proteosome-mediated Degradation of the Multicopper Oxidase Hephaestin. J Biol Chem 279: 25696-25702.

Nose Y, Kim B-E and Thiele DJ (2006a) Ctr1 drives intestinal copper absorption and is essential for growth, iron metabolism, and neonatal cardiac function. Cell Metabol 4: 235-244.

Nose Y, Rees EM and Thiele DJ (2006b) Structure of the Ctr1 copper trans'PORE’ter reveals novel architecture. Trends Biochem Sci 31: 604-607.

Nose Y, Wood LK, Kim B-E, Prohaska JR, Fry RS, Spears JW and Thiele DJ (2010) Ctr1 is an apical copper transporter in mammalian intestinal epithelial cells in vivo that is controlled at the level of protein stability. J. Biol. Chem. In press.

Petris MJ, Smith K, Lee J and Thiele DJ.(2003) Copper-stimulated Endocytosis and Degradation of the Human Copper 
Transporter, hCtr1. J Biol Chem 278: 9639-9646.

Prohaska JR (1983) Changes in Tissue Growth, Concentrations of Copper, Iron, Cytochrome Oxidase and Superoxide

Dismutase Subsequent to Dietary or Genetic Copper Deficiency in Mice. J Nutr 113: 2148-2158.

Puig S, Lee J, Lau M and Thiele DJ (2002) Biochemical and Genetic Analyses of Yeast and Human High Affinity Copper Transporters Suggest a Conserved Mechanism for Copper Uptake. J Biol Chem 277: 26021-26030.

Puig S and Thiele DJ (2002) Molecular mechanisms of copper uptake and distribution. Curr Opin Chem Biol 6: 171180.

Rae TD, Schmidt PJ, Pufahl RA, Culotta VC and O'Halloran TV (1999) Undetectable Intracellular Free Copper: The Requirement of a Copper Chaperone for Superoxide Dismutase. Science 284: 805-808.

Robinson NJ and Winge DR (2010) Copper Metallochaperones. Annu Rev Biochem 79: 7.1-7.26.

Rosenzweig AC and O'Halloran TV (2000) Structure and chemistry of the copper chaperone proteins. Curr Opin Chem Biol 4:140-147

West EC and Prohaska JR (2004) Cu,Zn-Superoxide Dismutase Is Lower and Copper Chaperone CCS Is Higher in Erythrocytes of Copper-Deficient Rats and Mice. Exp Biol Med 229: 756-764.

Zimnicka AM, Maryon EB and Kaplan JH (2007) Human Copper Transporter hCTR1 Mediates Basolateral Uptake of Copper into Enterocytes; implications for copper homeostasis. J Biol Chem 282: 26471-26480. 